\title{
NASA's Space Launch System: Progress Toward Unmatched Exploration Capability
}

\author{
John Honeycutt, ${ }^{1}$ and Chris Cianciola ${ }^{2}$ \\ Space Launch System Program, Marshall Space Flight Center, AL, 25812 USA
}

\begin{abstract}
The Space Launch System (SLS) Program delivered the first element of the explorationclass rocket and completed manufacturing of all major structural elements in 2017. The Program continues component integration and testing in 2018 in preparation for the inaugural launch of NASA's new deep space exploration system in fiscal year 2020. SLS represents a new strategic national capability designed for the most challenging human and robotic exploration and is engineered for overall mission success. This paper will discuss the technical and programmatic successes and challenges of the past year and look ahead to plans for 2018 and 2019.
\end{abstract}

\section{Introduction}

On Dec. 11, 2017, the President signed National Space Policy Directive 1 calling for NASA to "lead an innovative and sustainable program of exploration with commercial and international partners to enable human expansion across the solar system and to bring back to Earth new knowledge and opportunities. Beginning with missions beyond low-Earth orbit, the United States will lead the return of humans to the Moon for long-term exploration and utilization, followed by human missions to Mars and other destinations." NASA is working with domestic and international partners to solve the great challenges of living and working in space farther from Earth, and in the process creating new knowledge that benefits all of humanity and inspires the nation. NASA is planning to build the in-space infrastructure for long-term exploration and development of the Moon by accelerating to 2022 plans to deliver to lunar orbit a power and propulsion element as the foundation of a Gateway human-tended outpost in lunar orbit. Gateway will provide a strategic presence in lunar space that will drive activity with commercial and international partners and help further explore the Moon and its resources and translate that experience toward human missions to Mars. NASA is developing the key capabilities to support beyond-Earth exploration with the Space Launch System (SLS), the Orion crew spacecraft, and upgraded spaceport facilities at Kennedy Space Center (KSC) as shown in Figure 1.

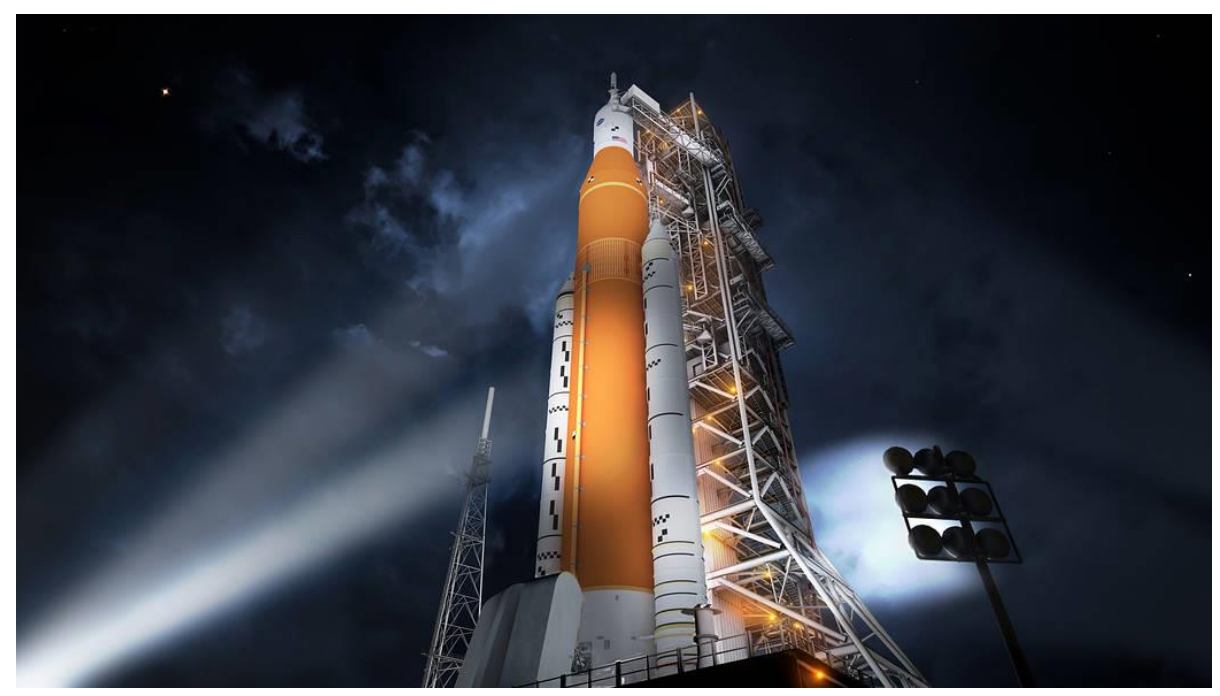

Fig. 1. Artist concept of SLS and Orion on the mobile launcher at KSC.

\footnotetext{
${ }^{1}$ Manager, Space Launch System Program.

${ }^{2}$ Deputy Manager, Space Launch System Program.
} 
Human exploration of deep space requires a large vehicle that can carry huge payloads needed for complex missions farther away from Earth than humans have ever ventured. SLS will carry more mass and volume than any launch vehicle since the Apollo Saturn V. Its unmatched capability will reduce the complexity, cost, and risk associated with payload design, ground infrastructure, and in-space operations, and the vehicle will enable more ambitious human and robotic exploration. SLS is built on the most powerful and proven propulsion system in the world. It has the versatility to support human and robotic missions, launching spacecraft, habitats and supporting systems to a variety of deep space destinations. It is designed to be safe and affordable, taking advantage of NASA's more than five decades of investments in technology, facilities and America's greatest asset: its high-tech skilled workforce. Not only will SLS be able to launch the Orion spacecraft to the Moon, but on its first flight it will also carry $136 \mathrm{U}$-sized CubeSat science and technology demonstration payloads. A Unit $=10 \mathrm{~cm}$ x $10 \mathrm{~cm}$ x $10 \mathrm{~cm}$. The EM-1 mission provides a rare opportunity for these small satellites to reach deep space destinations, as most launch opportunities for CubeSats are limited to low-Earth orbit (LEO).

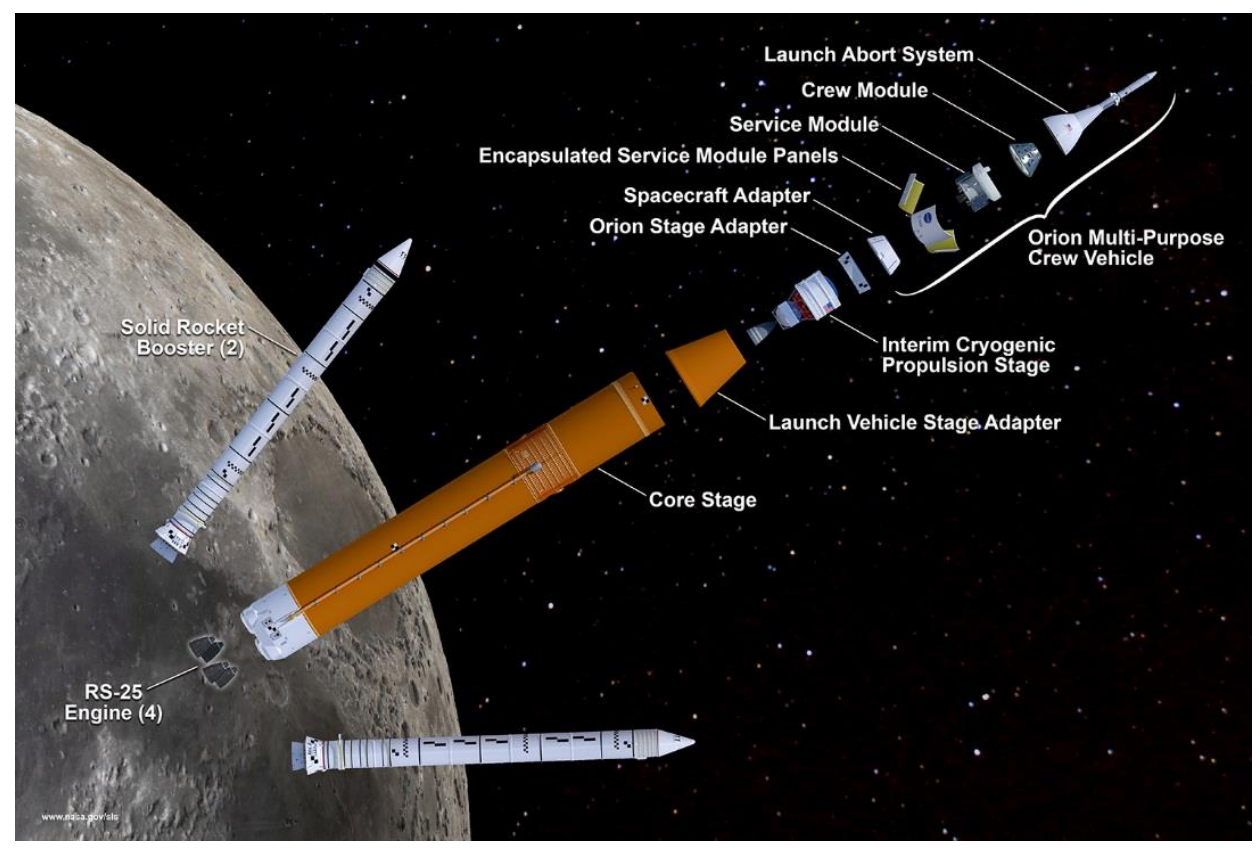

Fig. 2: Expanded view of the SLS Block 1 configuration for EM-1.

SLS is designed to evolve as exploration missions become more challenging. The initial SLS configuration, Block 1 (Fig. 2), will provide more than 26 metric tons (t) of payload mass to trans-lunar injection (TLI), more than any current launch vehicle. That capability will grow significantly as SLS is upgraded to an interim Block 1B capability of 34-40 $t$ to TLI and to its ultimate Block 2 capability of more than $45 \mathrm{t}$ to TLI. Likewise, SLS payload volume for the cargo configurations will increase from more than 200 cubic meters $\left(\mathrm{m}^{3}\right)$ to more than $900 \mathrm{~m}^{3}$. Unique to SLS, Block 1B is designed to deliver in a single mission the crewed Orion spacecraft plus large systems such as habitats needed for living and working in deep space as co-manifested payloads. The vehicle evolutionary path is shown in Figure 3. 


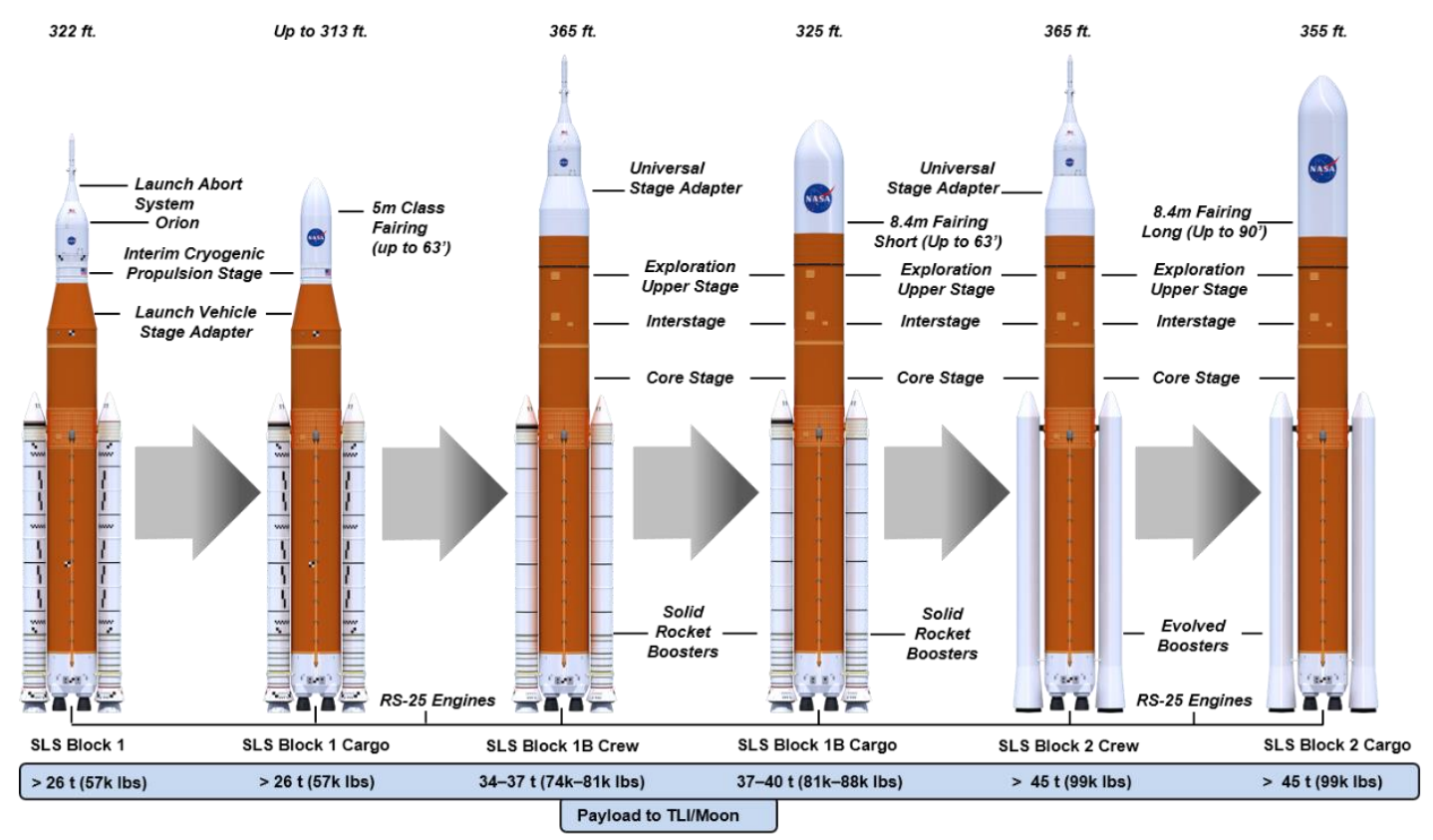

Fig. 3: The SLS vehicle evolution path illustrating the increasing mass and volume capability.

In a change from the original plan to launch Block 1 uncrewed and Block 1B crewed on the first two missions, NASA has chosen to use the Block 1 configuration for the first three SLS missions:

- Exploration Mission-1 (EM-1) will be the first integrated test flight of the SLS and the uncrewed Orion, currently planned to launch in fiscal year 2020.

- Exploration Mission 2 (EM-2) will be the first crewed flight of SLS and Orion and will take humans farther into deep space than ever before, currently planned to launch in 2023.

- Additionally, under consideration for the second or third flight of SLS is its first science mission, launching the Europa Clipper robotic probe to investigate the habitability of Jupiter's icy moon Europa onboard an SLS Block 1 cargo vehicle.

Congress passed and the President signed a spending bill for the remainder of 2018 that provides NASA \$350 million to build a second Mobile Launcher (ML) for SLS designed to support the Block 1B configuration. The second ML for Block 1B allows NASA to accelerate the SLS launch schedule for the first three missions using Block 1 rockets and the first ML while the ML for Block 1B is under construction.

The following sections will discuss progress to date on SLS manufacturing and testing, as well as related progress toward flight.

\section{Program Status}

The SLS Program is managed at NASA's Marshall Space Flight Center (MSFC) in Huntsville, AL. Between 2017 and 2018, SLS moved from design and manufacturing into assembly, integration and testing. All major hardware components for the EM-1 core stage, engines, boosters, and in-space stage are structurally complete, and the first flight hardware has been delivered to KSC. Flight software is progressing through testing, and the SLS Engineering Support Center (SESC) at MSFC is conducting testing to ensure connectivity with other mission-related facilities around the country.

\section{A. Liquid Engines}

Four RS-25 engines, located in the base of the rocket each supply 512,000 pounds of vacuum thrust at 109 percent rated power. Manufactured by Aerojet Rocketdyne, they will operate for the roughly eight-minute trip to orbit. NASA selected the RS-25 engine, powered by liquid hydrogen $\left(\mathrm{LH}^{2}\right)$ and liquid oxygen (LOX), based on its power, known performance over 135 space shuttle missions including more than a million seconds of ground and flight operating time, and adaptability to the SLS mission. Sixteen engines from the shuttle program are available to power the first four SLS missions. 
Unlike the shuttle program, the engines will not be reused. The program has restarted engine production with the goal of developing an expendable engine costing at least 30 percent less than the shuttle era engines. These engines will be certified to operate at 111 percent of the original engine's rated power, or roughly 521,000 pounds of thrust. By updating manufacturing tools, eliminating many of the materials and processes associated with reusability, and employing new techniques such as additive manufacturing, the program is well on its way to achieving the cost reduction goal.

An "adaptation" program using two development engines and completed in 2016 at NASA's Stennis Space Center (SSC) demonstrated that the engines will meet requirements to operate effectively at the colder temperatures and higher inlet pressures of the SLS environment versus the shuttle environment. Hotfire testing continued in 2017 to gain confidence, green run two new engines and certify new state-of-the-art engine controllers and software. The four EM-1 engines and their controllers are currently at SSC awaiting shipment to NASA's Michoud Assembly Facility (MAF) when needed for integration with the core stage. Hotfire testing continues in 2018 in order to green run new controllers and test new components for the restart engines such as an additively-manufactured pogo accumulator and a new hot isostatic pressure (HIP) bonded main combustion chamber. (Fig. 4)

The four RS-25 engines for the EM-1 mission have completed processing and are awaiting shipment from SSC to MAF for EM-1 core stage integration. Processing is under way on the EM-2 flight set.

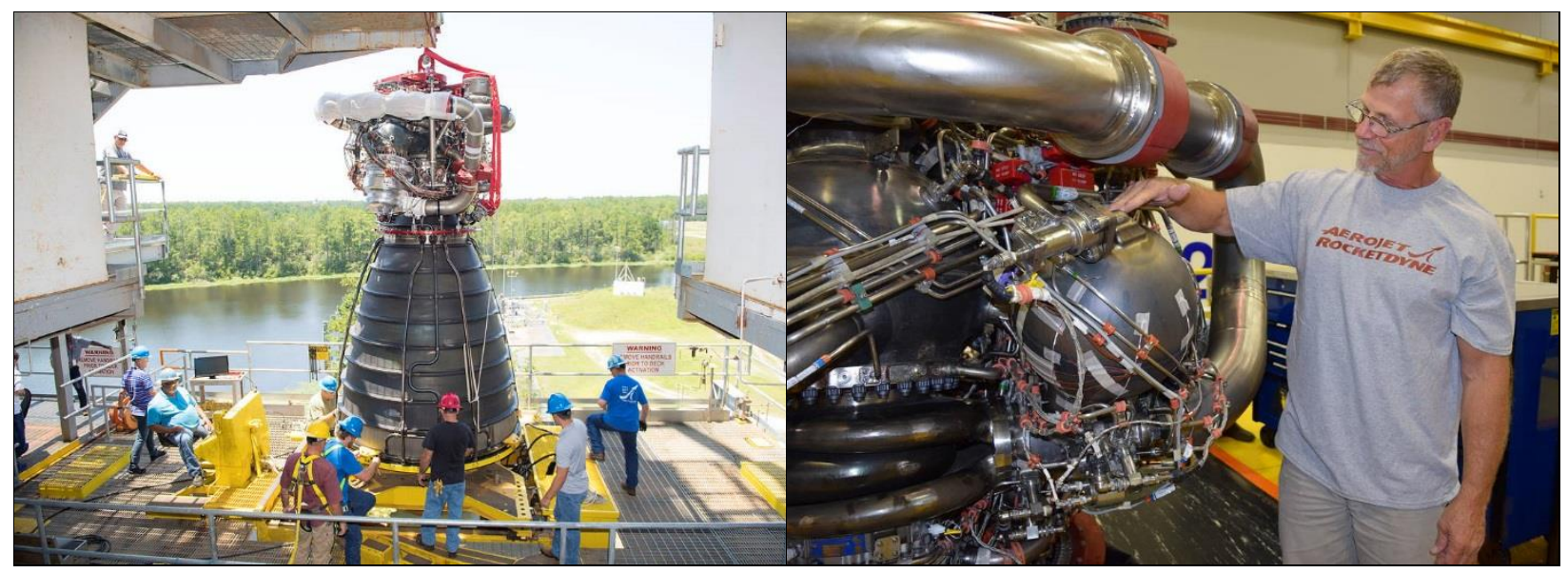

Fig. 4. RS-25 for 2018 test series is installed in the test stand at SSC, left. Additively-manufactured spherical pogo accumulator is shown in place on the engine, right.

\section{B. Boosters}

The five-segment solid rocket boosters for SLS are the largest ever made for flight, approximately 53.9 meters (m) tall and $3.6 \mathrm{~m}$ in diameter, and manufactured by Northrop Grumman. A pair of boosters for each SLS mission generates a total of approximately 7.2 million pounds of thrust, more than 75 percent of the vehicle's total thrust at liftoff. The boosters notably also carry the entire weight of the rocket on the launch pad. After burning roughly six tons of polybutadiene acrylonitrile (PBAN) propellant every second, the boosters burn out after roughly two minutes and are jettisoned. Unlike the shuttle boosters, they are not designed for recovery.

The five-segment motor is based on the four-segment space shuttle motor. Changes to the heritage design include additional propellant, a different propellant grain tailored for the SLS mission, asbestos-free case insulation, an updated avionics system, and improved non-destructive evaluation techniques to confirm flight readiness.

Seven of 10 motor segments for EM-1 mission are complete, and the last three segments are in final processing. Motor casting for EM-2 is underway. The EM-1 exhaust nozzle assemblies are complete. Igniter installation is under way. The forward assemblies for the EM-1 boosters are almost complete at KSC. Each forward assembly consists of the forward skirt, frustum, nose cone, avionics, and four solid fuel separation motors. Additionally, technicians at KSC are building up the thrust vector control (TVC) systems for installation in the aft skirts. Avionics are qualified at the system level and will be tested with core stage avionics in upcoming testing. 


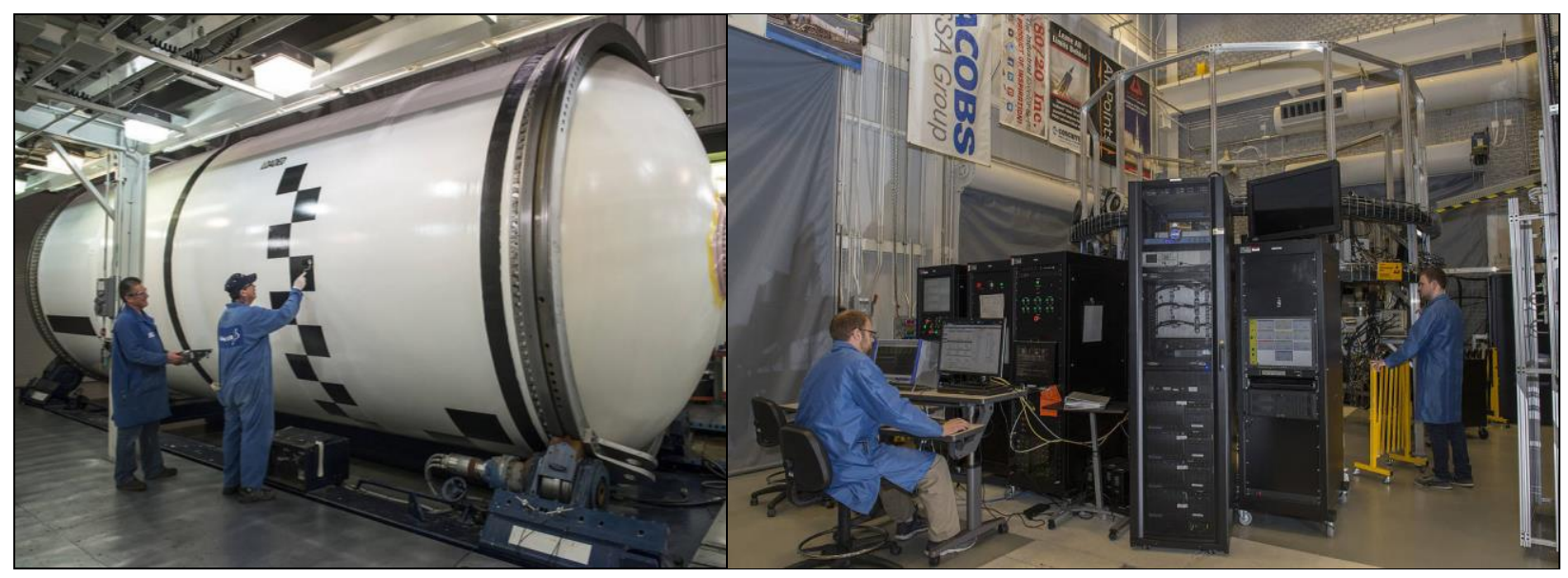

Fig. 5. Workers apply photogrammetric markings to a completed motor segment, left, and booster avionics undergoing qualification testing, right.

\section{Stages}

The SLS core stage is the only totally new design on the vehicle and it is the largest rocket stage in the world. Designed and manufactured by Boeing, the stage is $64.6 \mathrm{~m}$ tall and $8.4 \mathrm{~m}$ in diameter. It contains the four RS-25 engines, flight avionics, and propellant tanks and serves as the attach point for the boosters. The stage carries two million liters of $\mathrm{LH}^{2}$ and 742,000 liters of LOX.

The stage is manufactured at Michoud as five main subassemblies, from bottom to top: engine section, $\mathrm{LH}^{2}$ tank, intertank, LOX tank and forward skirt. Booster attach points are located on the engine section and the intertank. All subassemblies are welded, except the intertank, which is a bolted structure. Manufacturing is streamlined by the use of six major manufacturing tools: Circumferential Dome Weld Tool, Gore Weld Tool, Enhanced Robotic Weld Tool, Vertical Weld Center, Segmented Ring Tool and Vertical Assembly Center (VAC).

All major core stage hardware for structural testing and EM-1 is manufactured. The major sections are in various stages of cleaning, priming, thermal protection system (TPS) spraying, and installation of brackets, thrust structure, ducts, cabling, flight instrumentation and other equipment. (Fig. 6) The forward skirt is complete and its avionics have successfully been powered up. Workers are installing the TVC control system, pumps, manifolds, ducts and wiring harnesses in the engine section. The hydrogen tank has been proof tested, cleaned and primed. The oxygen tank was being sprayed with TPS foam.

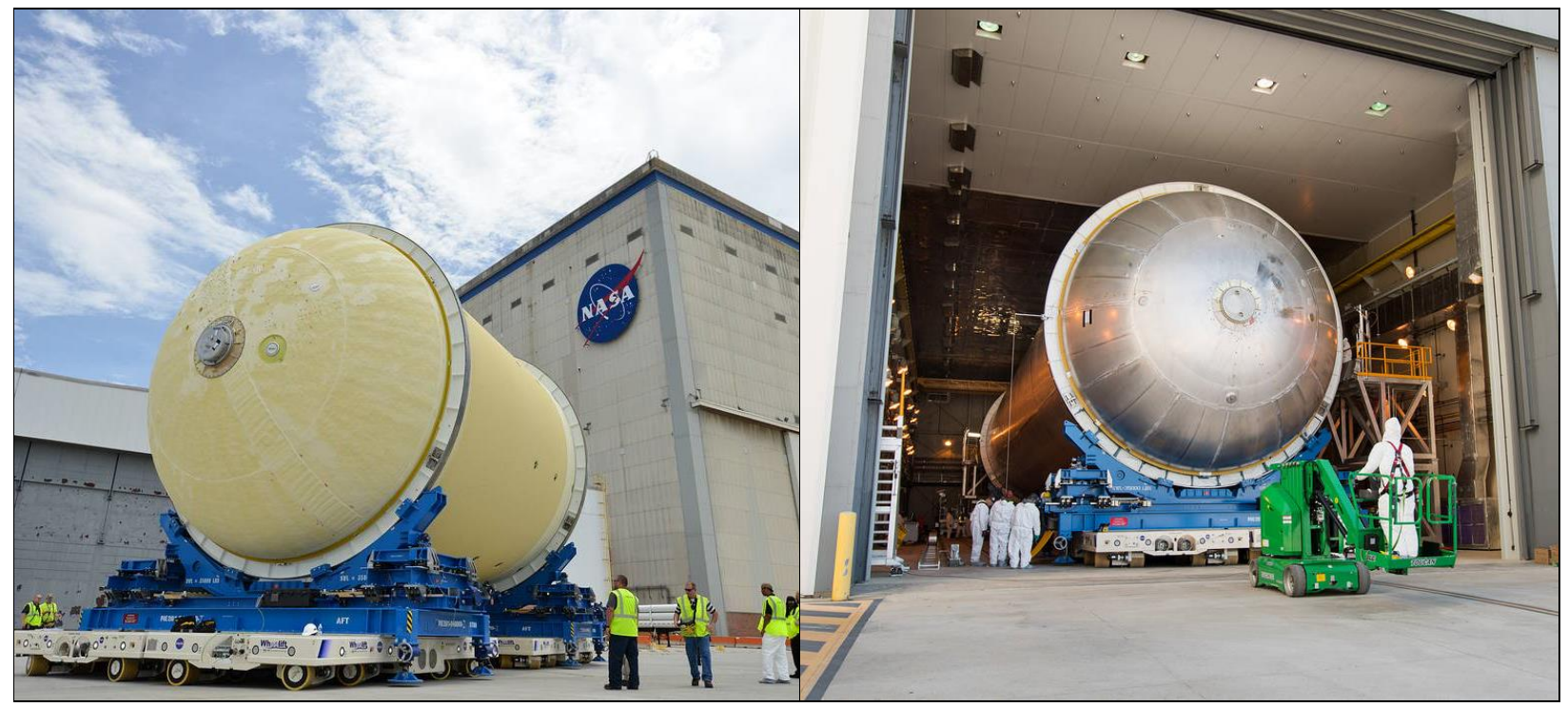

Fig. 6. EM-1 LOX tank moves after thermal protection foam application, left. The $\mathrm{LH}^{2}$ tank moves into a manufacturing cell for priming and thermal protection foam, right. 
The major components will be bolted together in two major subassemblies before being bolted into the completed stage. The forward section, consisting of the intertank, LOX tank and forward skirt will assembled in 2018. The aft section consists of the engine section, boat tail fairing, and $\mathrm{LH}^{2}$ tank and is scheduled for completion in early 2019. Both joins will be made in vertical assembly cells, after which they will be lowered horizontally for final integration in spring 2019. The flight stage is then scheduled to be shipped to SSC for green run hotfire testing in 2019 before the trip to KSC for flight integration and launch.

A significant aspect of core stage development is full-scale structural testing at MSFC of the major subassemblies. New test stands or facilities were built for all sections except the forward skirt, which is tested by analysis and are ready to support testing. All test articles are structurally complete. The first test article to arrive at Marshall was the engine section. Roughly 59 test cases were successfully completed in 2017 and early 2018, demonstrating the structure could support more than three million pounds of engine thrust loads and up to 750,000 pounds of loads created by the boosters. More than 3,000 channels of data provided data to validate the engine section design.

The intertank test article arrived at MSFC in early 2018. The newly constructed test stand for the intertank test article uses about 100 actuators to impart up to roughly eight million pounds of force to simulate flight loads. The first load cases were under way at the time this paper was written. The planned test series includes 21 influence (50 percent loads) test cases, including one cryo test case, and 20 mechanical test cases. Limit (100 percent loads) and ultimate (140 percent loads) test cases are scheduled to be completed by the end of 2018. The $\mathrm{LH}^{2}$ and LOX test articles were in assembly at MAF at the time of writing and scheduled to be shipped to MSFC in 2018 to begin testing.

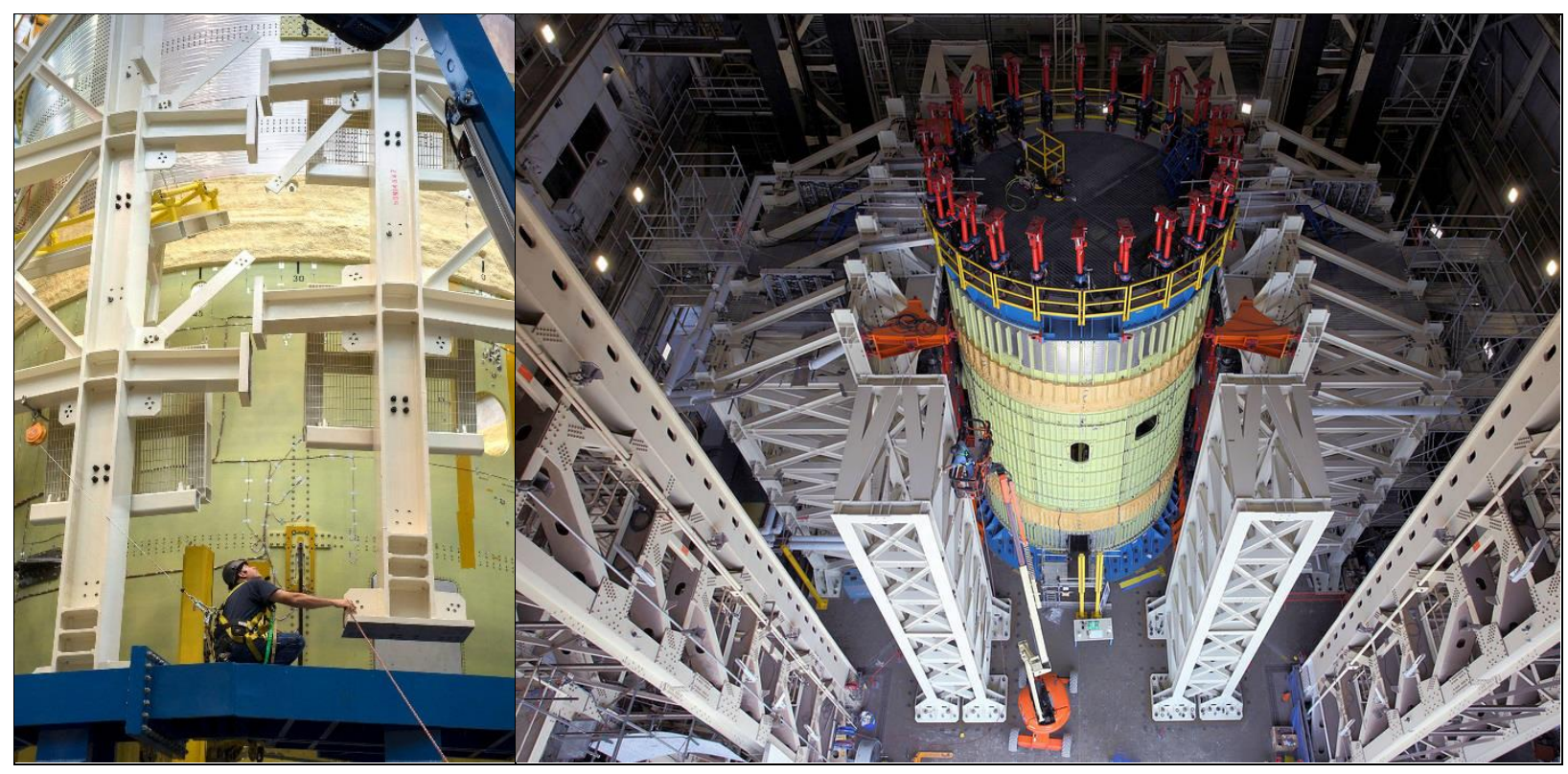

Fig. 7. Engine section structural test article, left, and intertank structural test article, right, shown during testing at Marshall Space Flight Center.

The core stage pathfinder was built and delivered to MAF in 2017 to begin practice operations with core stage ground support equipment for moving, lifting and transporting the EM-1 core stage.

The B2 test stand at SSC has been renovated to support core stage green run testing. EM-1 core stage sections will begin integration for "green run" hotfire testing at SSC in 2019.

\section{Upper Stage, Adapters and Payloads}

The SLS upper stage is the Interim Cryogenic Propulsion Stage (ICPS), which will perform the TLI burn for the EM-1 mission. During launch, it will be protected by the Launch Vehicle Stage Adapter (LVSA). The Orion Stage Adapter (OSA) will connect the ICPS to the Orion crew vehicle's service module. 
Manufactured by Boeing and United Launch Alliance, the ICPS is based on the existing Delta Cryogenic Second Stage and modified with lengthened hydrogen tank, hydrazine bottles for attitude control, and related avionics modifications. The EM-1 ICPS was completed in 2017 and delivered to KSC for processing. (Fig. 8)

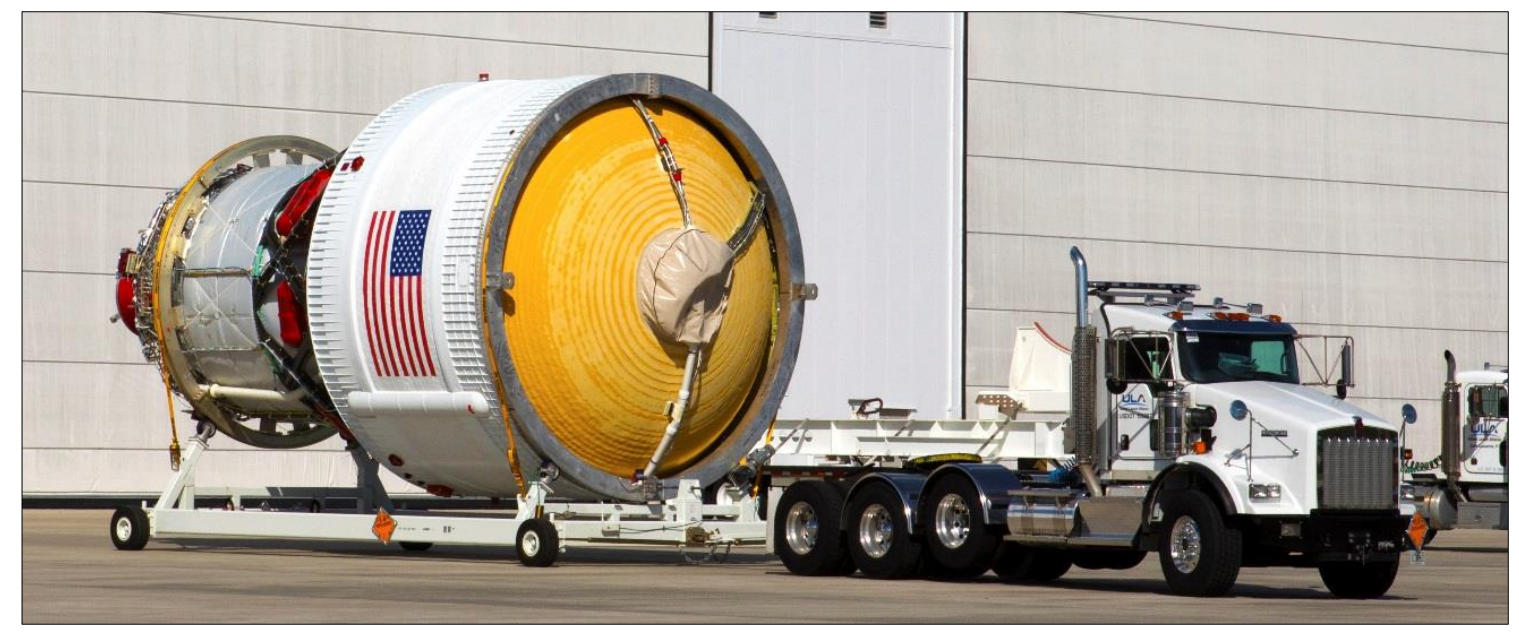

Fig. 8. The ICPS was the first EM-1 hardware turned over to KSC in April 2017.

The LVSA is structurally complete, and workers are installing actuators and mating the adapter to a frangible joint assembly. The OSA was completed and shipped to KSC in early 2018. It is ready for installation of 13 shoebox-sized CubeSat secondary payloads that will be deployed at several "bus stops" along the ICPS trajectory. SLS is providing a secondary payload deployment system consisting of the avionics unit and cubesat mounting brackets.

Structural testing at Marshall in 2017 included completion of engine section testing, as well as testing the components of the in-space stage. The first major structural test completed was the Integrated Structural Test, which comprised the LVSA, frangible joint assembly, ICPS and OSA. The ICPS test article was pressurized with nonreactive liquid nitrogen rather than volatile $\mathrm{LOX}$ and $\mathrm{LH}^{2}$. Twenty-eight hydraulic actuators subjected the stack to tension, bending, twisting, shear, and compression forces as high as 500,000 pounds of force during a series of more than 50 tests.

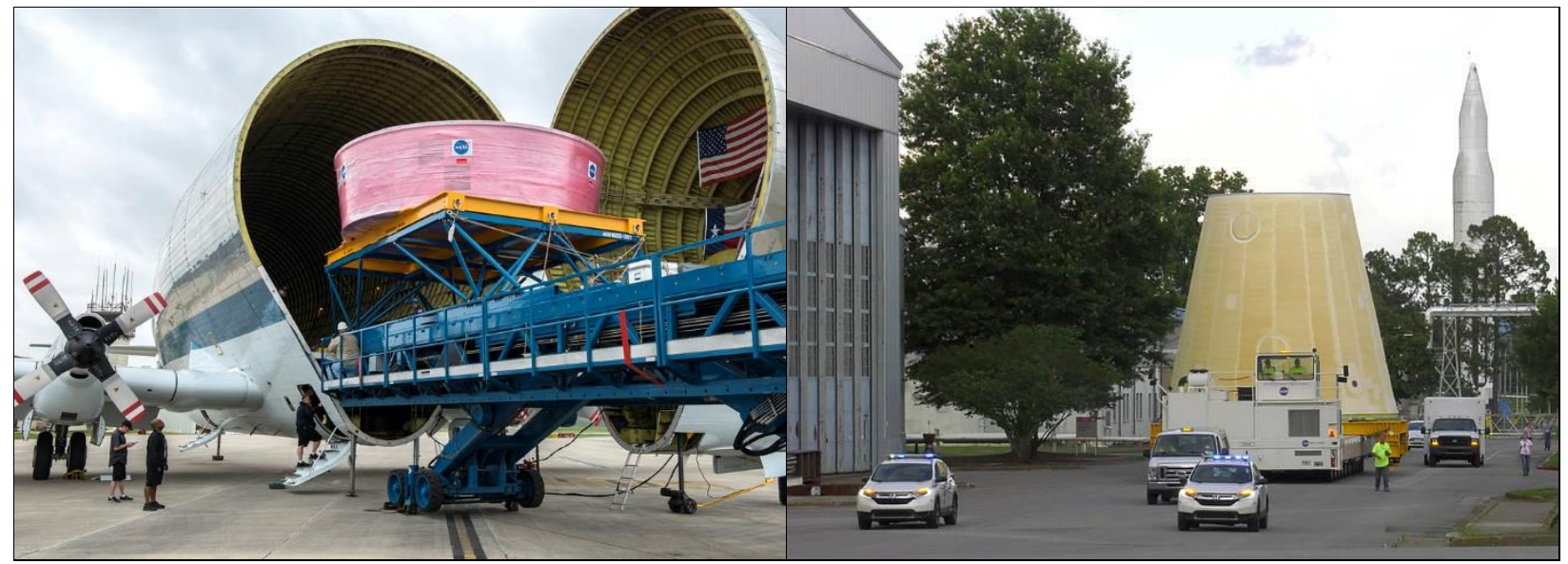

Fig. 9. The EM-1 OSA leaves MSFC for KSC in April 2018, left, while the EM-1 LVSA moves from TPS insulation to equipment installation at MSFC. 


\section{Conclusion}

NASA is leading the next steps in human exploration with missions to the Moon, where astronauts will build and begin testing the systems needed for challenging missions to other destinations, including Mars and beyond. SLS is vital to human and robotic exploration of deep space. It is built on the most powerful, proven propulsion systems in the world. It's unmatched mass and volume capability will reduce the complexity, cost, and risk associated with payload design, ground infrastructure, and in-space operations. The launch vehicle for the first mission is under construction and in testing now. Initial flight hardware has been delivered to KSC for processing. Manufacturing for the second launch vehicle is also under way. The planned first launch of SLS in fiscal year 2020 represents an important first step back into the solar system for human exploration. (Fig. 10) Along with the Orion crew vehicle and next-generation spaceport facilities, SLS will open an exciting new era of space exploration, bringing with it new knowledge and new discoveries.

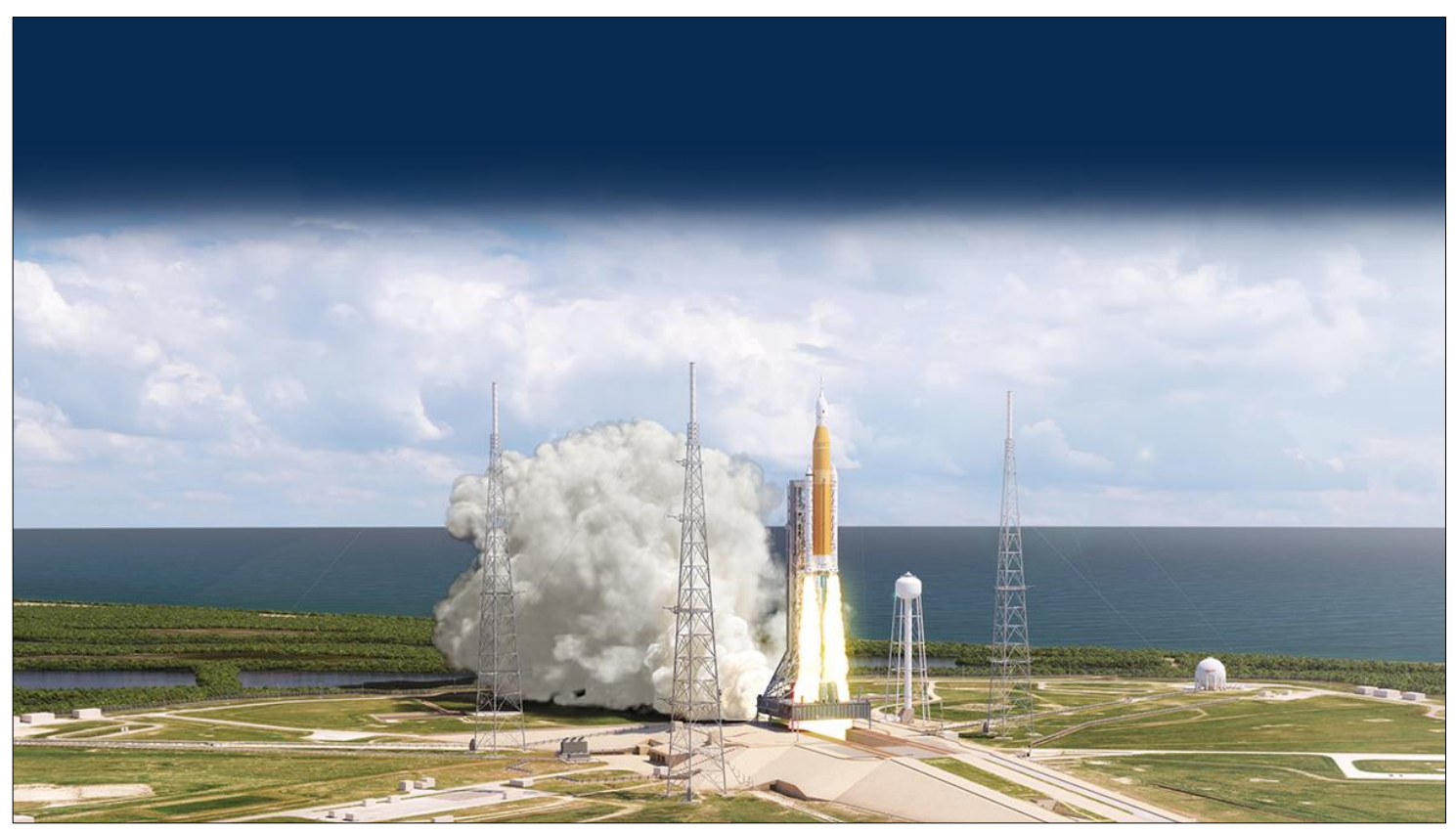

Fig. 10. Artist rendering shows a wide-angle view of the liftoff of EM-1 from Kennedy Space Center. 